\title{
Exon 46-48 Deletion of DMD Gene - A Boon in Beckers Muscular Dystrophy
}

\section{Trimal Kulkarni, Siddu Charki, Siddarameshwar S Kalyanshettar, Shankargouda V Patil and Mallangouda M Patil}

Department of Paediatrics, Shri B M Patil Medical College Hospital and Research Centre, Vijayapur, Karnataka, India

\section{Correspondence:}

Trimal Kulkarni

Department of Pediatrics,

BLDE (DU),

Shri B M Patil Medical College Hospital and Research Centre,

Vijayapur, Karnataka, India.

Email: Trimal.kulkarni@gmail.com

DOI: $10.3126 /$ jnps.v41i2.35321

Submitted on: 2020-08-06

Accepted on: 2021-02-26

Acknowledgements: None

Funding: Nil

Conflict of Interest: None declared

Permission from IRB: Yes
To cite this article: Kulkarni T, Charki S, SS Kalyanshettar, SV Patil and MM PatilExon. Exon 46-48 Deletion of DMD Gene - A Boon in Beckers Muscular Dystrophy. J Nepal Paediatr Soc. 2021;41(2):286-9.

\begin{abstract}
Becker's muscular dystrophy (BMD) has wide spectrum of presentation from asymptomatic to severe progressive muscular weakness. Subtle weakness can be missed in busy outpatient units. Traditionally muscle biopsy is used for definitive diagnosis. But it is invasive and less helpful in genetic counseling of inherited dystrophinopathies compared to genetic studies. Newer techniques like next generation sequencing (NGS) also help in understanding many phenotype-genotype co-relations. We describe here a seven year boy who presented with mild weakness, without any evidence of cardiomyopathy and had exon 46 - 48 deletion on NGS.
\end{abstract}

Keywords: Becker's muscular dystrophy (BMD); exon deletion 46 - 48; next generation sequencing 


\section{INTRODUCTION}

Weakness in children may have various etiologies like nutritional, metabolic, endocrinal and muscular dystrophy / myopathies. Becker's muscular dystrophy (BMD) is a $\mathrm{x}$-linked recessive dystrophinopathy occurring due to mutation in $\mathrm{Xp} 21$ dystrophin gene which encodes the protein dystrophin. BMD has a spectrum of presentation from isolated hyperckemia, subtle muscular weakness cramps, myoglobinuria to progressive muscular disease. Unless there is significant disability, cases can be missed in busy outpatient practice. These phenotype - genotype correlations are seen depending on which domain of the gene has mutation.

Newer genetic studies like next generation sequencing (NGS) must be preferred since they are helpful not only in diagnosis but also, for prognosis and genetic counselling as compared to traditionally used muscle biopsy. NGS is almost non - invasive and less time consuming. The mean age of presentation in BMD is 11 years (Range two to 22 years) and for ambulation is 27 years (Range12 to 30 years). Earlier studies have shown mean age of onset of cardiomyopathy in BMD is 32 years ( 23 to 43 years).

We present one such case of BMD who had deletion of exon 46 - 48 in dystrophin gene. Children with this deletion variant have better prognosis of longer ambulation and cardiomyopathy also develops latter in such individuals as compared to cases due to other Mutations.

\section{CASE REPORT}

A seven year old boy weighing $17.2 \mathrm{~kg}$, born out of non-consanguineous marriage, came with mother

Table 1. Muscle bulk in child

\begin{tabular}{|lrr|} 
Circumference in cm & Right & \multicolumn{1}{l}{ Left } \\
\hline Midarm & $14 \mathrm{~cm}$ & $14 \mathrm{~cm}$ \\
Midforearm & $12 \mathrm{~cm}$ & $12 \mathrm{~cm}$ \\
Midthigh & $27 \mathrm{~cm}$ & $27 \mathrm{~cm}$ \\
Midleg & $22 \mathrm{~cm}$ & $22 \mathrm{~cm}$
\end{tabular}

and his maternal uncle with history of weakness noticed since he was four years old. Mother noticed that child appeared to be slow in running, and was apprehensive to climb or jump down as compared to peers. Now he had difficulty to raise from sitting but could comb his hairs and put on his shirt and buttons. There was no history of scholastic backwardness, constipation, rash, chronic drug ingestion or pain on exertion. Family history was normal. Birth history and antenatal scans were normal. Child's weight was on third centile and height on $25^{\text {th }}$ centile (WHO). Motor milestones like neck holding, walking, climbing, running were attained at appropriate age and there were no speech and cognitive delay.

On examination, he was conscious, oriented and thin built with no dysmorphism. General examination showed normal vitals with mild pallor and hypertrophied calf muscles. CNS exam

Table 2. Power across joints in child

\begin{tabular}{|llrr} 
Joint & \multicolumn{1}{c}{ Movement } & Right & Left \\
\hline Shoulder & Flexion & $4 / 5$ & $4 / 5$ \\
& Extension & $4 / 5$ & $4 / 5$ \\
& Adduction & $4 / 5$ & $4 / 5$ \\
& Abduction & $4 / 5$ & $4 / 5$ \\
Elbow & Flexion & 5 & 5 \\
& Extension & 5 & 5 \\
Wrist & Flexion & 5 & 5 \\
& Extension & 5 & 5 \\
Hip & Flexion & $4 / 5$ & $4 / 5$ \\
& Extension & $3 / 5$ & $3 / 5$ \\
& Adduction & $4 / 5$ & $4 / 5$ \\
& Abduction & $4 / 5$ & $4 / 5$ \\
Knee & Flexion & 5 & 5 \\
& Extension & $4 / 5$ & $4 / 5$ \\
Ankle & Plantar flexion & 5 & 5 \\
& Dorsiflexion & 5 & 5 \\
& Inversion & 5 & 5 \\
& Eversion & 5 & 5 \\
& & & \\
& & 5 & 5
\end{tabular}




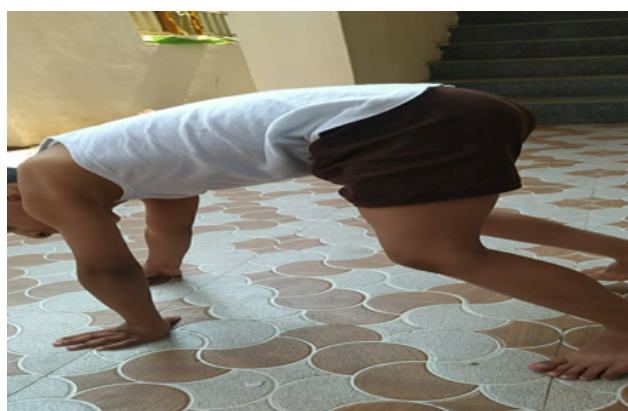

Figure 1. Gower's sign

revealed wasting of limb muscles, hypotonia and depressed deep tendon reflexes with flexor plantar.

Gower's sign was positive. Spine and rest of the systemic examination was normal. Initial investigations like complete blood count and thyroid function tests were normal. CPK levels were raised $(4000 \mathrm{mcg} / \mathrm{l})$. So, neurology consultation was taken and we did genetic studies i.e., next generation sequencing (NGS) since child was not co-operative for electromyography.

NGS showed deletion of exon 46-48 in dystrophin gene which was likely pathogenic for Beckers muscular dystrophy. Baseline echo was normal. Pulmonary function tests were advised but child did not co-operate. Mother was counselled about the benign nature of the disease. Patient was advised physiotherapy and follow up. Mother was advised for genetic studies and antenatal counselling before next pregnancy.

\section{DISCUSSION}

In school aged children presenting with lower motor neuron weakness Beckers muscular dystrophy should be considered.1,2 Other differentials could be limb girdle muscular dystrophy $^{3}$ (distal involvement and AR inheritance), facioscapulohumeral muscular dystrophy (face involvement and $\mathrm{AD}$ inheritance) and congenital myopathies presenting late in childhood (CPK normal). Raised serum creatine phosphokinase is important clue. Electromyography may not be feasible in resource limited setting or may have technical errors. Traditionally muscle biopsy is done for definitive diagnosis but we preferred newer genetic techniques. In this case next generation sequencing ${ }^{4,5}$ was done which showed

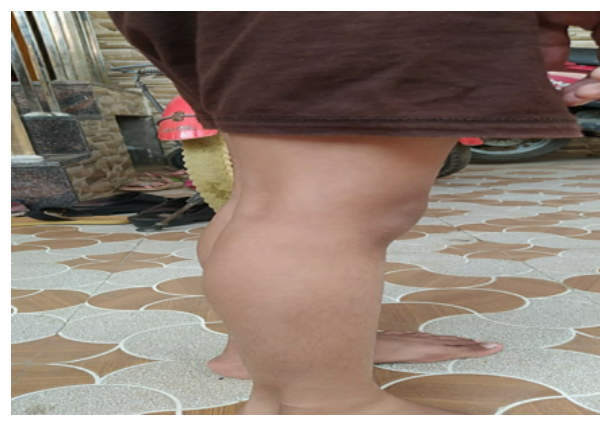

Figure 2. Hypertrophied calf muscle

exon deletion of 46 - 48 in dystrophin gene confirming diagnosis of Becker's muscular dystrophy.

NGS although costlier than muscle biopsy ${ }^{6}$ but was preferred as it is noninvasive and also helps in prognosis. NGS has been shown to be better ( $90 \%$ mutations detected) than other methods of genetic studies like multiplex ligation-dependent probe amplification (70\% mutations detected). ${ }^{7}$ NGS also helps in prognosis of the disease course depending on where and how the deletion occurred in the dystrophin gene hence it should be preferred especially when newer therapies like exon skipping is being used in trails and treatment. ${ }^{4,8}$

Earlier studies have shown that 'in frame mutations' produce milder Becker's phenotype and 'out of frame mutations' produce the severe Duchenne muscular dystrophy. ${ }^{2,4,8}$ In our case the exon deletion 46 - 48 was diagnosed in which mean age of ambulation is more than usual and Incidence of dilated cardiomyopathy was also seen to be less in such cases as compared to cases with other mutations..$^{4,9,10}$

Earlier studies have also shown usefulness of detecting such genotype - phenotype correlations. Absence of males affected in maternal family could be explained by fact that BMD may have spectrum of involvement like being asymptomatic in adult age, isolated hyperckemia and muscular cramps to severe muscle involvement (wheel chair bound). In our case isolated proband affection was seen which is hypothesised due to mutation occurring in egg at or following conception since mother was not willing to check her carrier status by genetic analysis. 


\section{CONCLUSIONS}

Becker's muscular dystrophy can present with subtle weakness, so high index of suspicion is required to diagnose it. Isolated proband can be seen affected with BMD although it is a X-linked disorder. Next generation sequencing (NGS) is better than muscle biopsy as we can understand genotype-phenotype correlations which help in prognosis and genetic counseling of the family. Cases with Exon 46 - 48 deletion have longer ambulatory status and less incidence of dilated cardiomyopathy.

\section{REFERENCES}

1. Menezes MP, North KN. Inherited neuromuscular disorders: Pathway to diagnosis. J Pediatr Child Health. 2012 june;48(6):458-65. DOI:10.1111/j.1440-1754.2011.02210.x.

2. Nicolas A, Raguenes-Nicol C, Ben YR, Ameziane-Le HS, Cheron A, Vie V, et al. Beckers muscular dystrophy severity is linked to structure of dystrophin. Hum Mol Genet. 2015 Mar;24(5):1267-79. DOI:10.1093/hmg/ddu537.

3. Schwartz M, Hertz JM, Sveen M, Vissing J. Lgmd 21 Presenting with acharacteristic duchenneor beckers muscular dystrophy phenotype. Neurology. 2005 May10;64(9):1635-7. DOI:10.1212/01.WNL.0000157654.59374.E5.

4. Taglia A, Petillo R, D’Ambrosio P, Picillo E, Torella A, Orsini C, et al. Clinical features of patients with dystropinopathy sharing the 45 - 55 exon deletion of DMD gene. Acta Myologica. 2015;34:9-13. PMC: 4478772.

5. Lim BC, Lee S, Shin JY, Kim JI, Hwag H, Kim KJ, et al. Genetic diagnosis of duchenne and beckers muscular dystrophy using next- generation sequencing technology. Comprehensive mutational search in asingle platform. J Med Genet. 2011 Nov;48(11):731-6. DOI:10.1136/jmedgenet-2011-100133.

6. Srivastava P, Malhotra KP, Hussain N, Malhotra HS, Kulshreshtha D, Anand A. Diagnosing muscular dystrophies. Comparison of techniques and their cost effectiveness. A multi-institutional study. J Neurosci Rural Pract. 2020 Jul; 11(3):420-429. PMC7394627.

7. Okubo M, Minami N, Goto K, Goto Y, Noguchi S, Mitsuhashi S, et al. Genetic diagnosis of duchenne / becker muscular dystrophy using next-generation sequencing. Validation analysis of DMD mutations. Hum Genet. 2016 Jun;61(6):483-9. DOI:10.1038/jhg.2016.7.

8. Koenig M, Begs AH, Moyer M, Scherpf S, Heindrich K, Bettecken T, et al. The molecular basis for duchenne Vs beckers muscular dystrophy: Correlation of severity with type of deletion. Amj Hum Genet. 1989 Oct;45(4): 498-506. PMC: 1683519.

9. American Academy of Paediatrics section on cardiology and cardiac surgery. Cardiovascular Health Supervision for Individuals Affected by Duchenne Or Becker Muscular Dystrophy. Pediatrics. 2005 Dec;116(6):1569-73. DOI: 10.1542/peds.2005-2448.

10. Mavrogeni S, Markousis-Mavrogenis G, Papavasiliou A, Papadopoulos G, Kolovou G. Cardiac involvement in duchenne muscular dystrophy and related dystrophinopathies. Methods Mol Boil. 2018;1687:31-42. DOI: 10.1007/978-1-4939-7374-3_3. 